\title{
Is the Forest Service Keeping Up With the Times?: Interest Group and Forestry School Perceptions of Post-NFMA Change in the United States Forest Service
}

\section{Elise S. Jones and Paul Mohai}

Interest groups involved in the Forest Service's 1990 Resources Planning Act (RPA) forest planning process and representatives from accredited forestry schools were surveyed via a written questionnaire on their perceptions of change within the Forest Service since 1976. Respondents felt that the agency had changed, particularly during the late $1980 \mathrm{~s}$ and early 1990s. Consumptive users perceived the change to be negative, while non-consumptive user groups and forestry schools felt it was somewhat positive, although they still felt the Forest Service had much further to go in this direction before achieving these groups' desired priorities for National Forest management. These results indicate that the agency is undergoing a net shift in direction towards increased emphasis on non-commodity forest uses. In general, external forces, such as Congress and the courts, were seen as having a greater impact on agency change than were sources of change within the agency itself. Forestry schools agreed most often with non-consumptive users, indicating that these programs may be undergoing a change away from their traditional focus on timber production. In addition to providing valuable insights on the subject of change in the Forest Service, these survey results locate areas of agreement and disagreement, and provide valuable feedback to the agency regarding its constituent groups' views about its performance in managing the National Forests.

Almost a century ago, the United States Forest Service (USFS) was charged with the responsibility of managing America's National Forests-a responsibility that has expanded to encompass 191 million acres, roughly $8 \%$ of the land area of the United States. Prior to the 1970s, the Forest Service, with its reputation for scientific objectivity and expertise in forest management, largely was free to manage the National Forests as it saw fit, with relatively little intrusion by Congress or the public (Parent, 1992; Ackerman, 1990). However, the environmental legislation of the 1970s opened up the Forest Service's decisionmaking process, allowing input and participation by the public and organized interest groups and opening up the courts as a vehicle through which they could hold the agency accountable to its new statutory obligations (Ackerman, 1990). This, combined with a growing environmental awareness, new scientific understanding in the field of natural resource management, and increasing demand for National Forest recreation and other non-commodity forest uses, has made the Forest Service the subject of increasing attack from a diversity of conflicting interests relating to how the nation's forests should be used and managed (Ackerman, 1990). A growing subject of debate is whether the Forest Service has evolved as an institution and adapted its management of the National Forests to reflect this changing social, political, and scientific climate.

Most studies of change within the USFS have surveyed agency employees for evidence of whether change has occurred (Mohai, Stillman, Jakes, \& Liggett, 1994; Kennedy, Krannich, Quigley, \& Cramer, 1993; Brown \& Harris, 1992a; McCarthy, 
Sabatier, \& Loomis, 1991; Culhane, 1977); there have been virtually no efforts to assess constituency groups' views on this topic. In addition, only a handful of studies have tried to identify the source of agency change. This study surveys outside interest groups that have been involved in the agency planning process on their perceptions of the magnitude, nature, and source of change within the agency by addressing the following five issues: (a) Has change occurred in the Forest Service? (b) If so, what is the source for this change; in particular, does it come from within or outside of the agency? (c) Do interest groups feel that the agency is headed in the right direction? (d) Does the agency have further to go? and (e) What are the likely sources of future desired change?

\section{Background}

\section{The Magnitude and Nature of Agency Change}

There are several schools of thought regarding whether or not the Forest Service is changing, and to what extent the agency is responsive to forces for change. Twight maintains that the agency has changed very little in the past few decades and is relatively immune to both external and internal forces for change, due to its entrenchment in a strong "value orientation" (Twight \& Lyden, 1988; Twight, 1983). Based on the German forest management principles of sustained yield and utilitarianism, this belief system includes the premise that timber is the most important output of a forest. Under Twight's theory of "consolidative behavior," the agency reacts to pressures for change by first trying to "control its environment" through a reemphasis of the values underpinning its existing policy, and then if that fails, it merely window-dresses an existing program or develops a new one that is in keeping with the agency's traditional values (Twight, 1983, p. 109). Along these same lines, Kennedy (1988) maintains that the Forest Service is characterized by "groupthink," the tendency of agencies to become "unduly proud, cohesive and confident" due to the discouragement of internal dissent and an emphasis on agency loyalty, resulting in a "rigid, predictable organization" resistant to change. Kennedy also concluded, however, that the passage of the National Environmental Policy Act (NEPA) and subsequent environmental legislation in the 1970s represented a "major legislative assault" on this traditional behavior mode, opening up the agency's decisionmaking both internally and externally.

Other scholars argue that the Forest Service is an adaptive, changing agency. Culhane maintains that the agency is responsive to external pressures for change due to the agency's desire to avoid conflict (Culhane, 1981). According to Culhane's "rule of anticipated reactions," a broad, diverse set of public interests preclude the Forest Service from being "captured" fully by any single user group but require it to be responsive to all. Clarke and McCool (1985) concur, crediting the agency's adaptiveness to changing public values as at least partially responsible for its achievement of "agency superstar" status. Mohai (1987) reconciles Twight and Culhane's two differing viewpoints in his 1987 analysis of public involvement data from the agency's Second Roadless Area Review and Evaluation (RARE II) wilderness proceedings, by concluding that reality lies somewhere between the two.

More recently, some researchers have analyzed quantitative measures to assess whether change has occurred within the Forest Service. In his analysis of USFS budget trends over the past decade, Farnham (1995) found that congressional appropriations, and to a lesser degree budget requests from the agency itself, have shown an increased emphasis on non-commodity management activities such as fish 
and wildlife, and recreation, and decreased emphasis on commodity activities such as timber production, although the total earmarked for the latter still significantly outweighs expenditures on the former. This trend of increasing emphasis on noncommodity uses and decreasing emphasis on traditional consumptive uses like timber production also was seen in an examination of on-the-ground management activities such as fish and wildlife habitat enhancement, recreation, and ecosystem management (Farnham, Taylor, \& Callaway, 1995) and timber management (Farnham \& Mohai, 1995).

Several recent studies have addressed the issue of agency change by measuring shifts in USFS employees' attitudes and values. For example, Brown \& Harris (1992a) found in their 1991 survey that district rangers and forest supervisors favored National Forest commodity outputs less and non-commodity uses more than they did in 1981, and expressed much more concern for the environment. Similarly, a comparison of various USFS employee surveys by McCarthy, Sabatier, and Loomis (1991) concluded that major changes in employee attitudes had occurred, particularly between 1981 and 1989 and with respect to timber production levels.

Nonetheless, despite evidence of change in employee values, these same surveys also find evidence of the institutional resistance to change of which Twight and others spoke. Mohai, Stillman, Jakes, and Liggett (1994) (see also Mohai \& Jakes, in press) compared what employees felt the most important use of the National Forests is to the agency with what they thought it should be. In their survey, more than $60 \%$ of both USFS line and staff employees selected timber as the forest use most important to the agency, but less than $22 \%$ felt that it should be; instead, more than $70 \%$ chose a non-commodity use, such as fish and wildlife, recreation, or water. Additionally, when employees were asked to identify the most important change that the agency still needed to make, the most frequent answer was "shifting emphasis from commodity to non-commodity uses of the National Forests" and "increasing public involvement efforts and increasing the agency's responsiveness to public needs" (Mohai Stillman, Jakes, \& Liggett, 1994, p. 17). Similar results were obtained in a 1992 survey by Kennedy, Krannich, Quigley, and Cramer (1993), which concluded that USFS employees at all levels within the agency felt the Forest Service "over emphasizes wood and grazing values, while under emphasizing wildlife, recreation and water more than the publics' or their personal multiple use priorities." In this same study, employees named the employee values that they felt the agency most rewarded as "be loyal," "meet targets," and "promote a good public image," while naming "professional competence," "care for healthy ecosystems," and "care for future generations" as the values the agency should reward (Kennedy, Krannich, Quigley, \& Cramer, 1993, p. 1).

\section{Sources of Agency Change}

In addition to trying to measure whether change has occurred within the Forest Service, a handful of scholars also have attempted to identify the source of that change. Many feel that the growth of external change agents, especially in recent years, represent the driving force for change (Farnham, 1995; Tipple \& Wellmann, 1991; Ackerman, 1990; Kennedy, 1988; Culhane, 1981). They point to such events as the listing of the northern spotted owl as a threatened species under the Endangered Species Act in 1990 and the controversy surrounding the subsequent court injunction on timber harvests in its habitat, the growing public concern about below-cost timber sales and the overseas export of raw logs, increases in administrative and judicial challenges of agency decisions, and the growing demand for National Forest recreation. External vehicles for change include a broad cast of characters-the 
courts, Congress, the White House, interest groups, and the general public. In particular, studies have found that both the courts and Congress have had a substantial influence on the agency (Farnham, 1995; Jones \& Taylor, 1995; Tipple \& Wellmann, 1991; Kennedy, 1988).

Others maintain that there are sources of change within the agency itself, in particular the relatively recent influx of new types of employees who differ markedly from the typical Forest Service employee described by Kaufman (1960) in the 1960s: a white, male forester schooled in utilitarian forestry. Agency workforce diversification efforts were stimulated by a variety of factors. NEPA and the National Forest Management Act (NFMA) mandated planning via interdisciplinary teams composed of "non-traditional" professionals specializing in areas other than forestry and range management (Thomas \& Mohai, 1995). Laws such as the Equal Employment Opportunity Act of 1972 and Civil Service Reform Act of 1978, and a court-ordered consent decree in 1981, also began forcing the agency to open its doors to more women and minorities (United States General Accounting Office, 1991). Thomas and Mohai (1995) found that the numbers of these historically underrepresented employee groups, particularly women, had increased significantly in recent years; however, there still was relatively little movement of these groups into leadership positions within the agency. Many scholars argue that these new employees bring values to the agency that differ from the agency's traditional value orientation, and that once a "critical mass" of these new employees has been achieved, they may catalyze the adoption of a new resource management paradigm within the agency (Thomas \& Mohai, 1995; Mohai, Stillman, Jakes, \& Liggett, 1994; Brown \& Harris, 1993; McCarthy, Sabatier, \& Loomis, 1991). Some point to the formation of the Association of Forest Service Employees for Environmental Ethics (AFSEEE) in 1989 as evidence of the impact of workforce diversification (Brown, 1993). Created by a disgruntled group of past and current USFS employees, AFSEEE's goal is to "forge a socially responsible value system for the Forest Service based on a land ethic which ensures ecologically and economically sustainable management" (Association of Forest Service Employees for Environmental Ethics, 1992, p. 1). In particular, Brown and Harris (1992b, pp. 231, 239) maintain that by advocating an "alternative resource management paradigm" differing from the agency's traditional mindset, AFSEEE is catalyzing an unprecedented "bottom-up reform movement" in the agency.

\section{The Role of Outside Interest Groups}

This study focuses on the perceptions held by outside "interest groups." This term is used generically to refer to all external, non-governmental organizations that have attempted to influence agency activities, and includes a wide range of interestsfrom environmental conservation and recreation to timber and mining production. These interests represent the agency's "user," or "clientele," groups. Although some of these represent private economic interests impacted directly by Forest Service resource management activities, many others serve as a conduit for the involvement and expression of opinions of different segments of the general public who have specific views about how they would like to use National Forests or see them managed. Following the trend of increased demand for public involvement in agency management decisions, many of these groups have increased substantially in both numbers and power over the past two decades (Dana \& Fairfax, 1980). They have acted to influence agency behavior in a variety of ways, including lobbying congressional legislators who have oversight over agency activities or funding, testifying as "expert witnesses" at congressional hearings, directly lobbying agency 
staff and officials, attending public hearings, organizing letter-writing campaigns to comment on Forest Service actions, and bringing lawsuits against the agency.

Perceptions held by informed and involved user groups can provide valuable insights into Forest Service change. Moreover, since these National Forest user groups can exert considerable influence on public policy decisions affecting forest management, via such activities as court challenges and lobbying, their perceptions, accurate or not, are a driving force behind the creation of policies directing the agency's management of the national forests.

Twight and Lyden's 1981 survey (1989) to measure Forest Service bias represents the most recent survey of these agency user groups. They surveyed agency constituents involved in the Forest and Rangeland Renewable Resources Planning Act of 1974 (RPA) planning process. Twight and Lyden lumped all respondents as either "environmentalists" or "forest utilizers" based on the organizations with which respondents allied themselves. The study found that the two sets of interest groups had widely divergent views about National Forest management, and that district rangers, who also were surveyed, were much more closely aligned with forest utilizers. However, since the Twight and Lyden survey was conducted more than a decade ago, and prior to the recent focus on the issue of change within the Forest Service, it provides little insight into this issue. As a result, this study was conducted to fill the void in research regarding constituent groups' perceptions and to complement recent surveys of Forest Service employees.

\section{Methods}

The target population was interest groups knowledgeable about and actively involved with Forest Service activities. The sample was drawn from the Forest Service's 1990 RPA mailing list-the list of organizations and individuals who have requested information about, commented upon, or were in some other way involved in the RPA planning process. Containing more than 1000 names, the list includes a wide range of citizens and interest groups, ranging from local environmental groups to national industry lobbying associations. Although not an exhaustive list of all Forest Service user groups, it provides a fairly good representation of the various kinds of groups interested in how the agency manages the National Forests. The groups composing it are distributed widely in both geography and size. Additionally, the 1990 RPA list mirrors the 1980 RPA list used by Twight and Lyden in their 1981 survey, and thus provides a basis of comparison with the earlier study.

All individuals on the RPA mailing list not representing an organization were excluded from the survey (Twight and Lyden surveyed individuals, but omitted all respondents not identifying with an organized user group). The primary reason for this exclusion was to increase our ability to categorize respondents easily and accurately into meaningful user groups for analysis. Organized user groups also generally have well-defined interests, a policy agenda, and resources to pursue it, all of which are likely to make them more influential in effecting changes in Forest Service policy. In addition, respondents who represent an organized user group, and hence are either employed by or volunteer their time to issues involving the National Forests, are likely to be more knowledgeable about the history and day-to-day workings of the Forest Service, and therefore potentially will be able to yield more useful insights on past and future change within the agency. All governmental agencies, universities, foreign government representatives, and congressional offices on the 1990 RPA list were 
excluded, as they do not qualify as traditional Forest Service user groups. The remaining 401 persons, all representing organizations, were sent questionnaires.

In a second stage of the study, questionnaires were sent to the heads of the 46 forestry programs in the United States accredited by the Society of American Foresters (SAF), so that a comparison could be made between the views of user groups and the people in charge of the forestry programs from which a significant portion of Forest Service employees graduate. The "head" of a forestry program was designated as the person most directly in charge of the program: either the dean of the forestry school or the top professor overseeing the forestry program, depending upon the organization of the particular program. Historically, many of the leaders of the Forest Service were drawn from the relatively small pool of forestry schools, which specialized in teaching the tenets of German forestry management, such as sustainable timber yield and utilitarianism (Dana \& Fairfax, 1980). Even today, the majority of USFS leaders receive their academic training in the field of forestry; Mohai, Stillman, Jakes, and Liggett (1994) found that $70 \%$ of all USFS line officers have a forestry degree. As a result, many scholars believe Forest Service foresters receive their first installment of agency "value orientation" in the SAF-accredited forestry schools (Twight, 1983).

The survey was conducted according to the Dillman (1978) procedure. The mailing consisted of a cover letter explaining the survey's purpose and a four-page written questionnaire to be returned to the authors within a five-day period. Questionnaires were sent in February 1993, and after two weeks a follow-up postcard was sent to each subject who had failed to respond. Phone calls then were made to all non-respondents for whom phone numbers could be obtained, to encourage them to complete the questionnaire, and a second survey also was mailed to all nonrespondents.

An effort was made to locate the correct mailing information for all questionnaires returned for incorrect addresses by the post office, and then to resend the questionnaire. If questionnaires were returned because the user group representative named on the mailing label had left the organization, a questionnaire was then re-sent addressed to the representative's job title, the person who had filled that position, or simply to "Forest Specialist," depending on the information available.

In spite of these efforts, correct mailing information could not be found for 22 groups for which questionnaires were returned due to outdated addresses. Investigations also failed to find any address or phone listings in either the Encyclopedia of Associations (1992) or telephone directory assistance for an additional 31 non-respondents; these groups were assumed to be no longer in existence. In the case of an additional 9 surveyed groups, written or telephone correspondence revealed that the contact person had left the organization and had not been replaced by a comparable forest specialist who was qualified to fill out the questionnaire for the group, thereby disqualifying the organization as "informed." The 62 organizations which fell into one of these three categories were dropped from the study. In all, 183 responses (or 54\%) of the adjusted total of 339 questionnaires were returned. Roughly $74 \%$ of the forestry schools-34 out of the potential 46 accredited schools-completed and returned the survey.

One of the survey questions asked respondents to "specify the nature or focus of the organization" for which they worked, and provided nine specific categories from which to choose, ranging from "environmental/conservation" to "timber production," as well as "other." Respondents then were lumped into "consumptive users" and "nonconsumptive users." Consumptive users included groups involved with timber, oil and gas, mineral, and rangeland livestock production; property rights advocacy; and motorized recreation, such as off-road vehicle use. Non-consumptive users included 
environmental and conservation organizations, and groups focused on non-motorized recreation and environmental education. If organizational categorization was unclear because respondents had failed to select a category on the questionnaire or had selected multiple categories, the organization's primary focus was researched in the Encyclopedia of Associations or via a phone call to the organization in question. Any respondent that still could not be categorized adequately was dropped from the final analysis. Thirteen respondents were dropped from the study for this reason. Many of these were representatives of Native American tribes, professional societies, or consulting firms. In the end there remained 101 responses from consumptive users and 70 from non-consumptive users.

Ideally, this study would have compared responses between different user types within the non-consumptive and consumptive user group categories, rather than just reporting the averages of the two major user categories. However, only one intracategory group within each major user category-timber interests and environmental advocacy organizations-would have been large enough (greater than 25 groups) to report separately. As a result, responses are reported for only the two major user categories and the forestry schools.

To encourage respondents to answer only those questions for which they were informed adequately, a "do not know" category was provided for all questions. Additionally, not every respondent replied to every question on the questionnaire. As a result, the response averages reported in the results section are calculated according to the number of respondents for each question, not the overall survey response rate. In addition, for all questions where appropriate, an "other" category was provided so that respondents had the opportunity to add information not thought of by the authors However, only a small fraction of respondents filled in the "other" category for any given question; hence the results of this category are not reported.

The survey asked 14 questions: 3 regarding the background of the respondent and 11 about perceived change in the Forest Service. This paper will discuss the results of 12 of these questions.

\section{Results and Discussion}

\section{Background Information on Survey Respondents}

Survey respondents generally were characterized by in-depth knowledge of and long-term familiarity with the agency and its management of the National Forests. Respondents in the non-consumptive category reported that they had been following Forest Service issues for an average of about 17.9 years; this figure rose to 23.9 years for surveyed consumptive users. During this time span, non-consumptive groups reported that they had been trying actively to influence agency decisions for an average of 11.9 years, while consumptive groups claimed a higher average of 18.6 years. In both categories, respondents were optimistic about their impact on the agency: $77 \%$ of non-consumptive groups and $56 \%$ of consumptive users who completed the survey question claimed their efforts had made a difference in influencing the Forest Service.

Similarly, forestry school respondents indicated long-term experience with the forestry profession, having worked an average of 19.2 years in an accredited forestry school. In addition, $74 \%$ had worked for the Forest Service, for an average employment length of 5.4 years. Nearly half (45\%) also reported working as professional foresters outside an accredited forestry school, averaging 8.5 years in this job category. 


\section{Perceptions of Change}

Respondents were asked whether they felt that change had occurred in National Forest management since the passage of NFMA in 1976; and, if so, for the better or the worse. Respondents were asked to circle a number on a scale of one to five, with three being "neutral," one being "significantly changed for the worse" and five being "significantly changed for the better." Responses then were averaged within each survey group (i.e., consumptive, non-consumptive, and forestry school).

The average values reported by the three groups were transformed onto a scale from 2.00 to -2.00 , with zero as the neutral point, to highlight whether the change was viewed as positive or negative. The absolute value of the average score for each group indicates the average magnitude of the perceived change. It is important to note that a finding of change does not indicate where on the consumptive/non-consumptive spectrum the user group sees the agency, just that there is net movement in one direction or another. Both the forestry school representatives and non-consumptive users felt that the Forest Service had changed slightly for the better, with average ratings of 0.44 and 0.54 above neutral. Consumptive users, on the other hand, were relatively more critical of the agency, and saw the Forest Service as changing for the worse, rating it on average at -0.87 . These results seem to indicate that, in the eyes of forest user groups, the agency has changed somewhat, and that on average this small change emphasizes a net shift on the part of the agency in the direction of environmental protection and non-commodity uses over commodity production.

\section{The Timing of Change}

The next question assessed when, during the 16-year period between 1976 and 1992, respondents felt that the most change had occurred within the Forest Service. All three groups felt strongly that most of the change had taken place between 1989 and 1992 , including $53 \%$ of forestry schools, $58 \%$ of non-consumptive users and $43 \%$ of consumptive users. Relatively few respondents indicated that significant change occurred within any of the other time periods indicated (1977-1980, 1981-1984, and 1985-1988). A more modest number of respondents felt that change had occurred throughout the entire period since passsage of NFMA $(27 \%, 13 \%$, and $31 \%$ of the three groups, respectively). This result seems to indicate that change in the agency has accelerated in recent years.

\section{The Nature of the Change}

Respondents also were asked to identify the change they felt had taken place since 1976. Specifically, they were asked to rate on a scale of one to five (where one is "significantly decreased emphasis on" and five is "significantly increased emphasis on") how they felt the Forest Service had changed its emphasis on nine different National Forest uses and objectives since 1976. These included five non-consumptive uses and objectives (watershed protection; recreation; wilderness, fish, and wildlife; endangered species protection; and biodiversity/ecosystem protection) and three consumptive uses (mineral, oil and gas production; timber production; and grazing/rangeland livestock production). Again, the values were transferred to a scale from -2.00 to 2.00 .

As seen in Figure 1, consumptive users felt that the Forest Service had increased its emphasis significantly on all of the non-consumptive uses, in particular endangered species protection, biodiversity/ecosystem protection, and wilderness, but had decreased its focus on consumptive uses, especially timber production. Responses from the forestry schools mirrored these trends, but with a smaller degree of perceived change in all categories. In contrast, non-consumptive users felt that the agency had 
increased its emphasis on all nine uses and objectives. They saw recreation, endangered species protection, fish and wildlife, watershed protection, and ecosystem protection as recipients of the greatest increase in agency attention, but in all nine categories indicated a significantly smaller magnitude of change than did consumptive users. Interestingly, non-consumptive users felt that, along with wilderness, the three consumptive uses (timber, mining, and grazing) had received the smallest average increases in emphasis by the agency.

The fact that all three groups rated all six non-consumptive uses as having received increased attention from the agency provides evidence of a net movement by the agency towards non-consumptive National Forest uses and objectives over consumptive ones, as was concluded in the previous question. Similarly, the fact that all three user groups rated the three consumptive uses as having received either decreases or only small increases in agency emphasis seems to point towards the same conclusion. These results complement Farnham's (1995) recent USFS budget analysis which found that most of the surveyed non-consumptive uses have seen increases in both agency budget requests and congressional appropriations. They also complement the results of Farnham, Taylor, and Callaway's (1995) analysis of USFS recreation, wildlife and fish management efforts and outputs and Farnham \& Mohai's (1995) analysis of USFS timber management activities.

\section{External Forces for Change}

The survey also attempted to assess the source of the perceived change by having respondents rate 26 external and internal forces for change. These particular forces were selected because they had been identified in various past studies as

\section{Figure 1}

Perceptions of Changes in Forest Service Emphasis on Different National Forest Uses and Objectives From 1976 to 1992

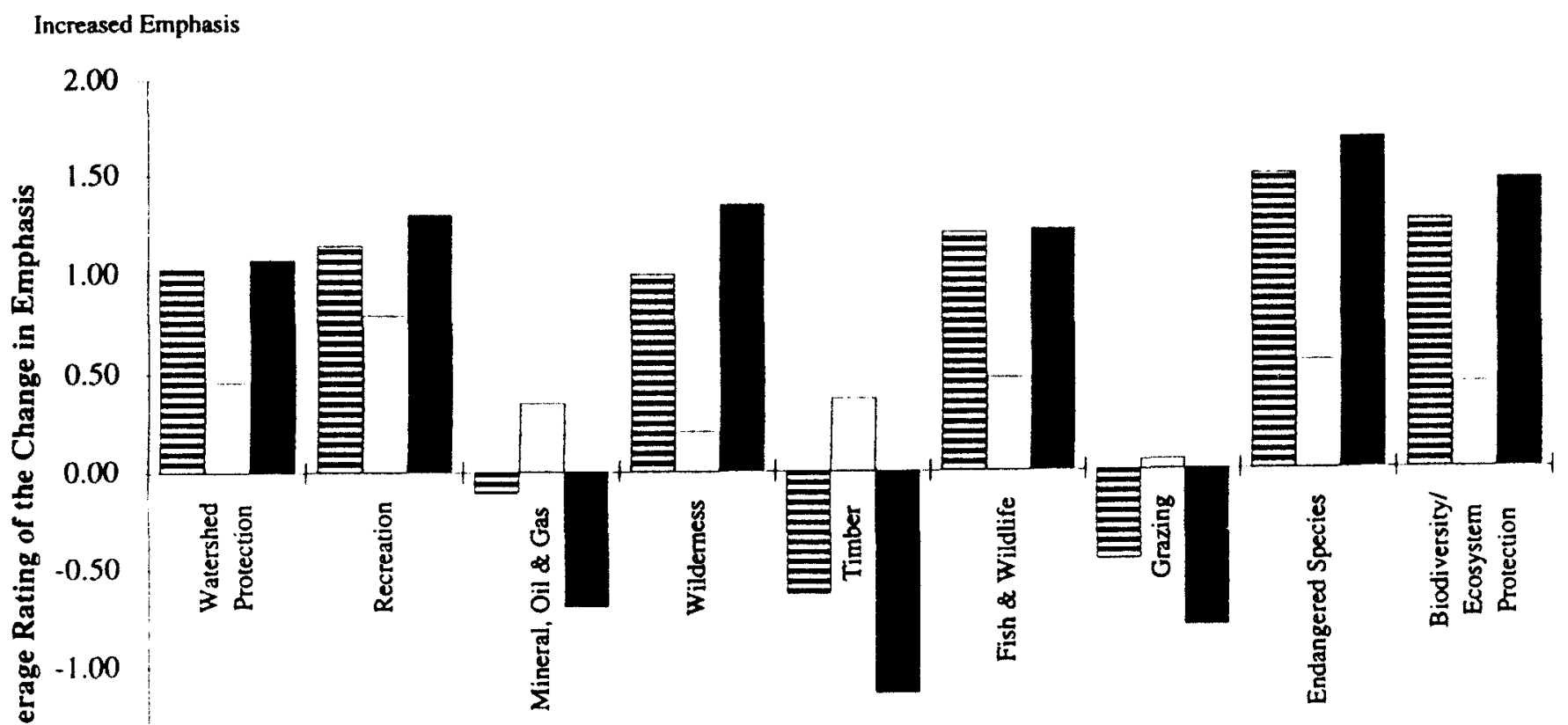

$-1.50$

$-2.00$

Decreased Emphasis

E Forestry Schools $\square$ Non-consumptive Users $\square$ Consumptive Users 
potential sources of change; the goal was to include as broad a list as was feasible (Farnham, 1995; Jones \& Taylor, 1995; Thomas \& Mohai, 1995; Brown \& Harris, 1993; Kennedy, 1991; McCarthy, Sabatier, \& Loomis, 1991; Tipple \& Wellmann, 1991; Ackerman, 1990; Kennedy, 1988; Culhane, 1981). Ratings corresponded to the amount of influence the respondent felt a given force had on change within the Forest Service. Again, respondents' ratings on a scale of one to five (one representing "significant negative influence" and five representing "significant positive influence") were superimposed on a scale from -2.00 to 2.00 , to illustrate whether the influence was perceived as positive or negative (when no bar is visible, the average perception of change was neutral).

Figure 2 illustrates perceptions of the degree of influence of 17 external forces, which consist of all three branches of government, commodity interests, environmental organizations, various federal agencies, recreation interests, the "wise use" movement, the public (the collection of United States citizens who are not affiliated with any interest group), the SAF, and forestry schools. The results show a number of interesting trends. All groups were in agreement that the White House and Congress have had a significantly negative influence on the Forest Service. Non-consumptive users were particularly critical of the White House, which likely is due to the fact that Presidents Reagan and Bush had reputations among environmental groups for being particularly insensitive to environmental concerns (Burkholder, 1992; Durbin, 1990).

The three surveyed groups were split widely in evaluations of many of the other external forces. This is illustrated particularly well by perceptions of the judicial system. Non-consumptive users rated the influence of the courts most positively, while consumptive users rated their impacts decidedly in the opposite direction. However,

\section{Figure 2}

Perceptions of the Extent of Influence of External Forces for Change on the Forest Service From 1976 to 1992

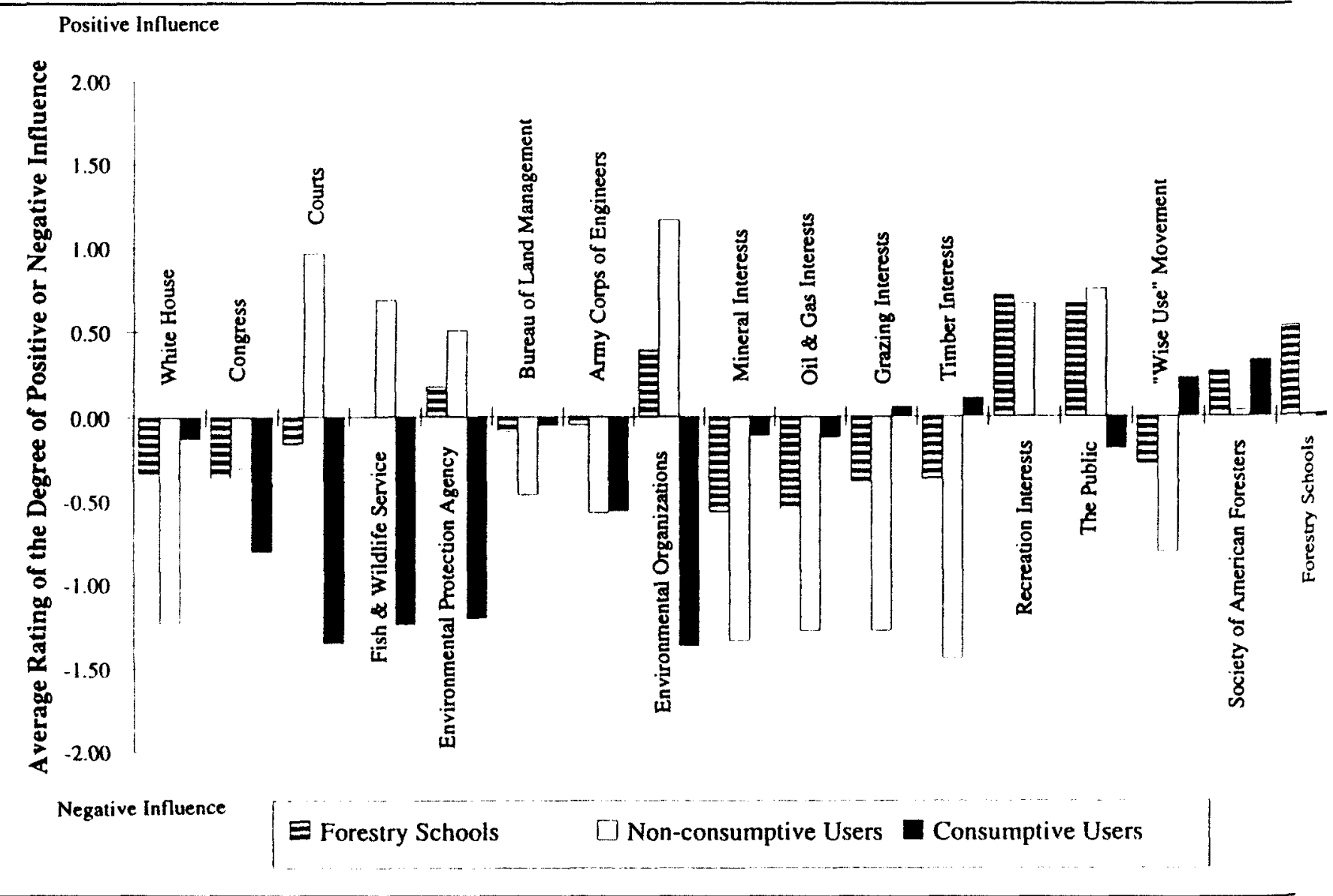


both groups viewed the courts as having a major influence on the Forest Service. In fact, courts received the second-most negative rating of any of the external forces from consumptive users and the second-most positive rating from non-consumptive users.

Consumptive users were not likely to rate positively any of the four mentioned federal agencies (Fish and Wildlife Service [FWS], Environmental Protection Agency [EPA], Bureau of Land Management [BLM], and the Army Corps of Engineers), and tended to see the FWS and EPA as being the most negative influences on the Forest Service. While non-consumptive and consumptive users agreed on the relative magnitude of the Corps' negative influence, non-consumptive users tended to rate the BLM more negatively than did consumptive users, and on average rated the EPA and FWS (two of the more environmentally-oriented federal agencies) as having a positive influence. Compared to perceptions of the other two user groups, the forestry schools tended to view the four agencies as having less impact on the USFS, seeing the FWS as having a neutral influence, the EPA as a positive influence, and the BLM and Corps as somewhat negative. Notably, all three groups were in agreement that on average the Corps and BLM have had an adverse effect on change within the Forest Service.

Not surprisingly, non-consumptive users tended to view themselves as significantly positive influences on change within the Forest Service, but viewed all four commodity users (mineral, oil and gas, range, and timber), as well as the "wise use" movement, as equally negative influences. It is interesting to note that the forestry school representatives agreed with the non-consumptive users in all six of these categories, seeing environmental organizations as a positive influence, and commodity production and the "wise use" movement as negative, although the degree of perceived influence in all categories was about half of that identified by non-consumptive users.

Consumptive users felt quite strongly that environmental organizations were exerting an adverse impact on the agency, rating them as having the most negative influence of any external change agents, but they were not particularly glowing about their own influence. The "wise use" movement, and timber and range interests, received positive marks, but both mineral interests and oil and gas interests were perceived by their fellow consumptive users as being slightly negative influences. These results appear to reflect the fact that consumptive users were not particularly cohesive, tended to favor their own particular commodity over others, and often did not view the impacts of the other consumptive users very favorably. Since timber interests comprised $45 \%$ of all consumptive use respondents, timber tended to receive higher marks than the other three commodity users, followed by grazing interests, which represented the next-largest group of consumptive survey respondents.

The forestry schools viewed their influence quite positively, but the two user groups perceived the forestry schools to have almost no influence, with both rating the forestry programs' impact as very slightly negative. This unexpected result seems to indicate that outside groups are unaware of the role that forestry schools play in training and socializing future USFS employees (see, for example, Twight, 1983). SAF represented one of the few sources of change on which all three groups were in agreement, with all giving it a rating of positive influence. Interestingly, the Society was perceived as having a more positive influence by consumptive users than by the forestry school representatives themselves, which the SAF accredits.

The forestry schools and non-consumptive users were in agreement in giving recreation interests a fairly highly positive ranking of influence, while consumptive users saw this entity as having a neutral impact on the agency. The non-negative rating by all three groups simply may reflect the fact that both user group categories contain recreationists; it also may indicate that recreation may be a forest use for which both non-consumptive and consumptive users share some common ground. 
Finally, the public evoked from non-consumptive users a highly positive rating for its impact on the agency, and a somewhat lower positive rating from forestry school representatives, but a negative score from consumptive users. These results were mirrored in the respondents' opinions on the impacts of public involvement on the Forest Service that are examined below. As discussed earlier, demands for increased public involvement in National Forest management and planning in the 1960s and 1970 s opened the agency's decisionmaking processes up to scrutiny and forced the agency to consider management views counter to its traditional mode of operations (Ackerman, 1990). Many of these new views were focused on non-commodity uses of the forests, which may explain the negative rating elicited from consumptive users.

\section{Internal Forces for Change}

Figure 3 illustrates respondents' perceptions of the influence of eight potential forces for change within the agency itself. These included the Forest Service Washington Office leadership; Washington Office staff; regional and district leadership; regional and district staff; researchers; AFSEEE; and non-foresters, women, and minorities hired since 1976.

Consumptive users, on average, rated each of the eight Forest Service entities as having a significantly negative impact on change within the agency. In particular, they saw AFSEEE as having an especially negative impact, followed by the agency's Washington Office leadership, and non-foresters. These findings complement earlier results, which found that consumptive users view the agency as changing for the worse.

\section{Figure 3 \\ Perceptions of the Extent of Influence of Internal Forces for Change on the Forest Service From 1976 to 1992}

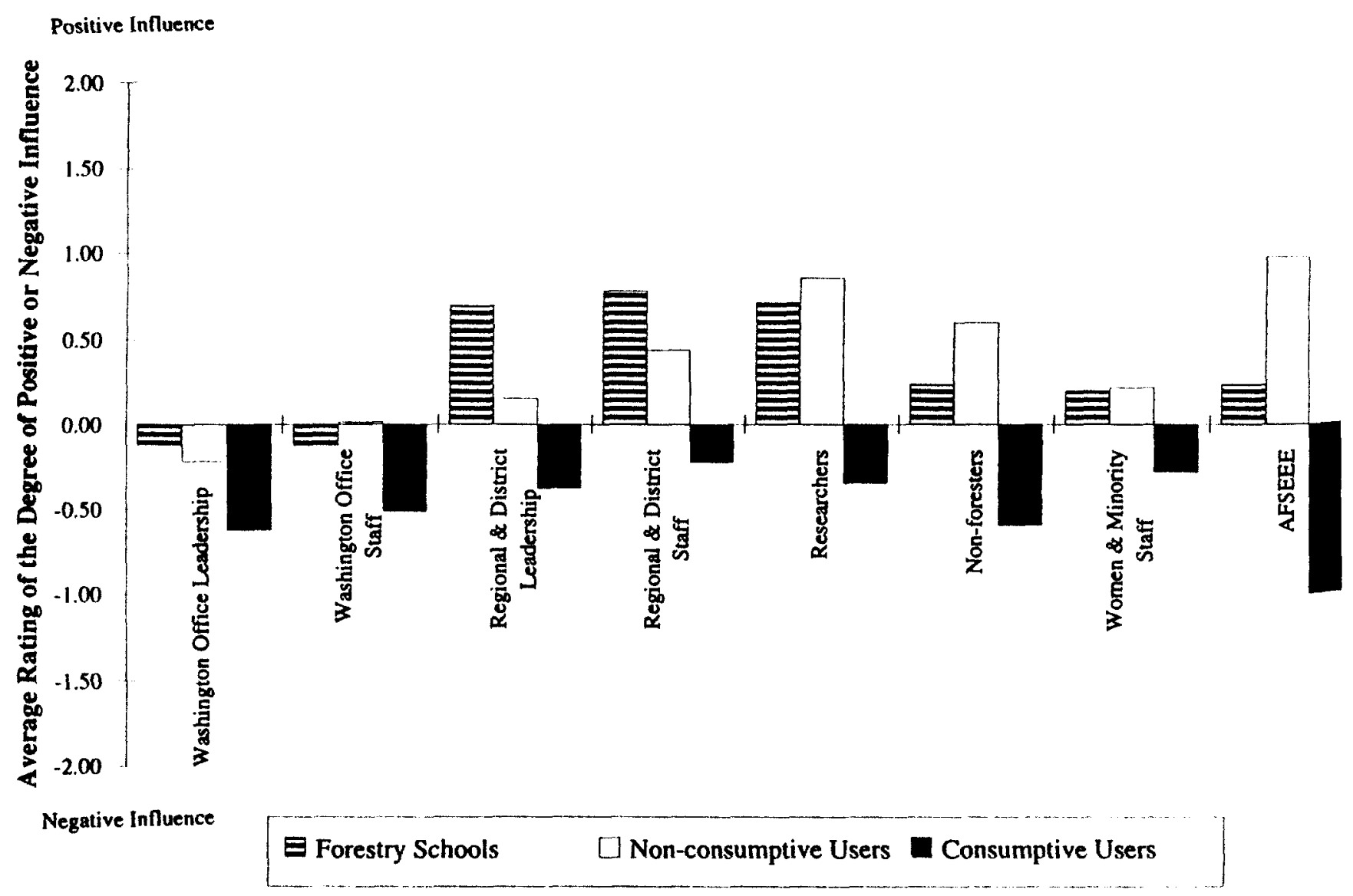


While non-consumptive users and the forestry schools tended to agree with consumptive users about the negative impact of the Forest Service's Washington Office leadership and staff, they saw the impact as less negative, and non-consumptive users even rated the staff's influence as very slightly positive. Even more notably, they ranked all other internal entities as having a definitely positive influence. The parallel opinions of the forestry schools and non-consumptive users are noteworthy, as well; the two surveyed groups differed only in the magnitude of the perceived influences. Forestry schools saw regional and district staff, agency researchers, and regional and district leadership as being the most positive internal change forces. Non-consumptive users, on the other hand, viewed the impact of AFSEEE most positively, followed by agency researchers, and non-foresters.

Finally, external forces are seen, on average, as having a much greater influence on the Forest Service than are internal forces (compare Figure 2 with Figure 3). This is indicated by the absolute magnitude of the average ratings, measured by their distance from the neutral point of zero in either the positive or negative direction (this is illustrated graphically by the length of the bars on the graphs). Excluding the "other" category responses, only one internal force received an average ranking with an absolute magnitude equal to or greater than one (i.e., $\geq+1$ or $\leq-1$ ) by any of the three user groups. This represents $4 \%$ of the total response averages for this question. In contrast, external forces were given average ratings with an absolute magnitude equal to or greater than one 11 times, representing $22 \%$ of the total response averages; $12 \%$ of these ratings ( 6 total) were 1.25 or greater.

\section{Impacts of Statutes and Activities on Change}

In a similar vein, the survey asked respondents to rate the perceived influence of six different processes and laws according to their effect on the agency. These included agency workforce diversification efforts, the agency's decentralized structure, public involvement, the forest planning process, legal challenges to agency actions, NEPA, and NFMA. Again, consumptive users viewed all categories as having a significantly negative impact on the Forest Service, particularly legal challenges to the agency and to NEPA (Figure 4). This parallels the consumptive users' previouslymentioned opinion of the impact of the courts and Congress. The forestry schools also shared a negative view of legal challenges, but in all other categories reported positive impacts, particularly for NFMA, NEPA, and public involvement. Non-consumptive users' conclusions were virtually the opposite of consumptive users in every categoryseeing public involvement, legal challenges, and NEPA as having the most positive influence on change within the Forest Service.

\section{Current Forest Service Priorities}

The next two questions asked respondents to rank what they thought were the current priorities of the Forest Service regarding various uses and objectives of the National Forests, and then to rank this same list of uses according to what they felt the agency's priorities ought to be. The purpose of these questions was to assess whether, in the view of the user groups, the agency is heading in the desired direction and whether additional agency change is desired.

The questionnaire instructed respondents to provide a mutually exclusive ranking (1-9) for each use or objective (an "other" category also was provided as an optional tenth category), with 1 being the highest priority and 9 the lowest. Despite these instructions, nearly 35 respondents gave more than one use category the same priority rank. In these cases, the duplicate ranking was attributed to each use, but 
lower-ranked uses correspondingly were downgraded in priority to reflect the actual number of uses ranked above. For example, if four uses were ranked " 1 ," then the use ranked " 2 " was given an adjusted ranking of five, the use ranked " 3 " was given a value of six, and so on.

\section{Figure 4}

Perceptions of the Extent of Influence of Various Processes and Statutes on Change in the Forest Service From 1976 to 1992

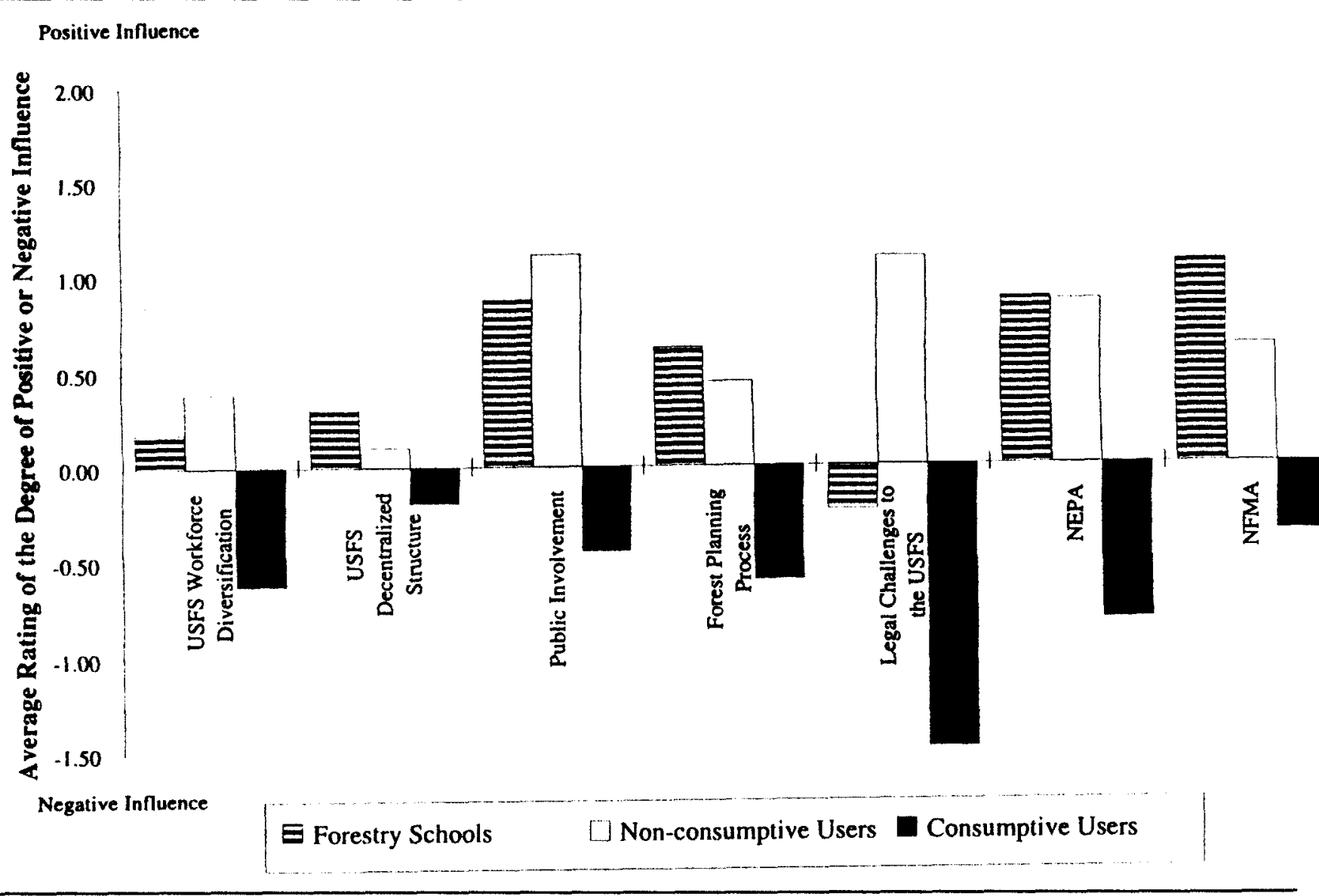

For the purposes of analysis, number-1 priorities were credited with 10 points, number-2 priorities with 9 points, and so on, with number- 10 priorities receiving only 1 point. This made perceived priority positively correlated with point rankings, which in turn allowed us to portray the results in a more graphically intuitive manner (Figures 5 and 6). A few respondents wrote multiple entries in the "other" category; in these instances, any use or objective receiving a priority rating of greater than 10 (such as 11 or 12) was credited with zero points in the analysis.

Figure 5 illustrates the results of the first question, with the size of the graph bars positively correlated with the priority of the ranking. Although earlier in the survey non-consumptive users indicated that they felt the agency was changing slightly for the better, the results from this question lead to the conclusion that they still feel the agency focuses primarily on commodity production. This is illustrated by the fact that three of the top four uses that they perceived as priorities of the Forest Service were commodities, with timber being viewed as the top priority, followed by grazing, and with mining tying for third with recreation.

Consumptive users, on the other hand, thought the Forest Service focused most strongly on environmental uses, highlighting endangered species protection as the agency's top concern, followed by biodiversity/ecosystem protection, recreation, and fish and wildlife. Forestry school representatives agreed somewhat with both groups; 
they felt that the Forest Service considered timber production a top priority, but deviated from non-consumptive users in designating watershed protection, recreation, and endangered species protection as the next agency priorities. The fact that recreation was rated in the top three Forest Service priorities by all three groups corroborates other studies, which have found that the agency has increased its emphasis on this activity, particularly in recent years (Farnham, Taylor, \& Callaway, 1995).

\section{Figure 5}

Perceptions of Current Forest Service Priorities for Different National Forest Uses and Objectives

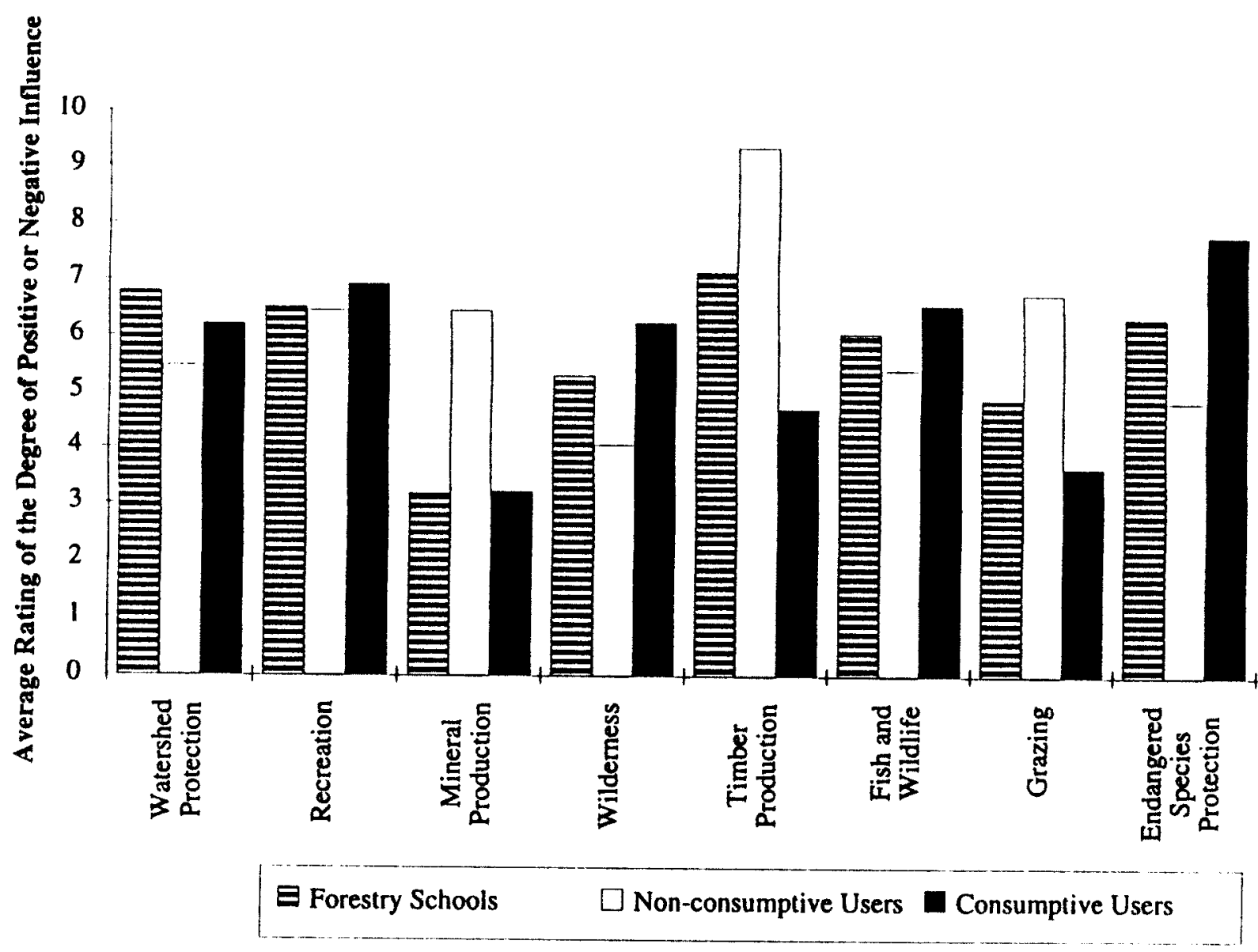

\section{Desired Forest Service Priorities}

Looking at the same list of National Forest uses and objectives, Figure 6 illustrates what the three user groups think the agency's management priorities for the National Forests ought to be. Biodiversity/ecosystem protection clearly was the topranked priority for both non-consumptive users and the forestry schools. Nonconsumptive users also felt strongly about watershed protection and endangered species, followed by fish and wildlife, recreation, and wilderness. They ranked the three commodities-timber, minerals, and rangeland-as their least important priorities. Conversely, consumptive users selected timber production as their top priority, but followed this with an emphasis on watershed protection and recreation that was fairly similar to the non-consumptive users. The forestry schools tended to split the difference between the two user groups, reflecting the non-consumptive users' emphasis on ecosystem protection, as well as their dislike for mining and grazing, but sharing the consumptive users' priority for timber production. That all three groups ranked watershed management as their number-two priority seems to validate the 
Policy Studies Journal, 23: 2

agency's new emphasis on planning and management at the watershed level. Similarly, the fact that all three groups thought recreation should be included among the top five priorities for the Forest Service indicates that some common ground exists among different National Forest users with this activity as well, and also bolsters the agency's increased emphasis in this area, as noted in the previous question. (See Mohai, Stillman, Jakes, \& Liggett, 1994, and Mohai \& Jakes, in press, for how Forest Service employees prioritized National Forest uses and objectives.)

\section{Figure 6}

Perceptions of What Forest Service Priorities for Different National Forest Uses and Objectives Should Be

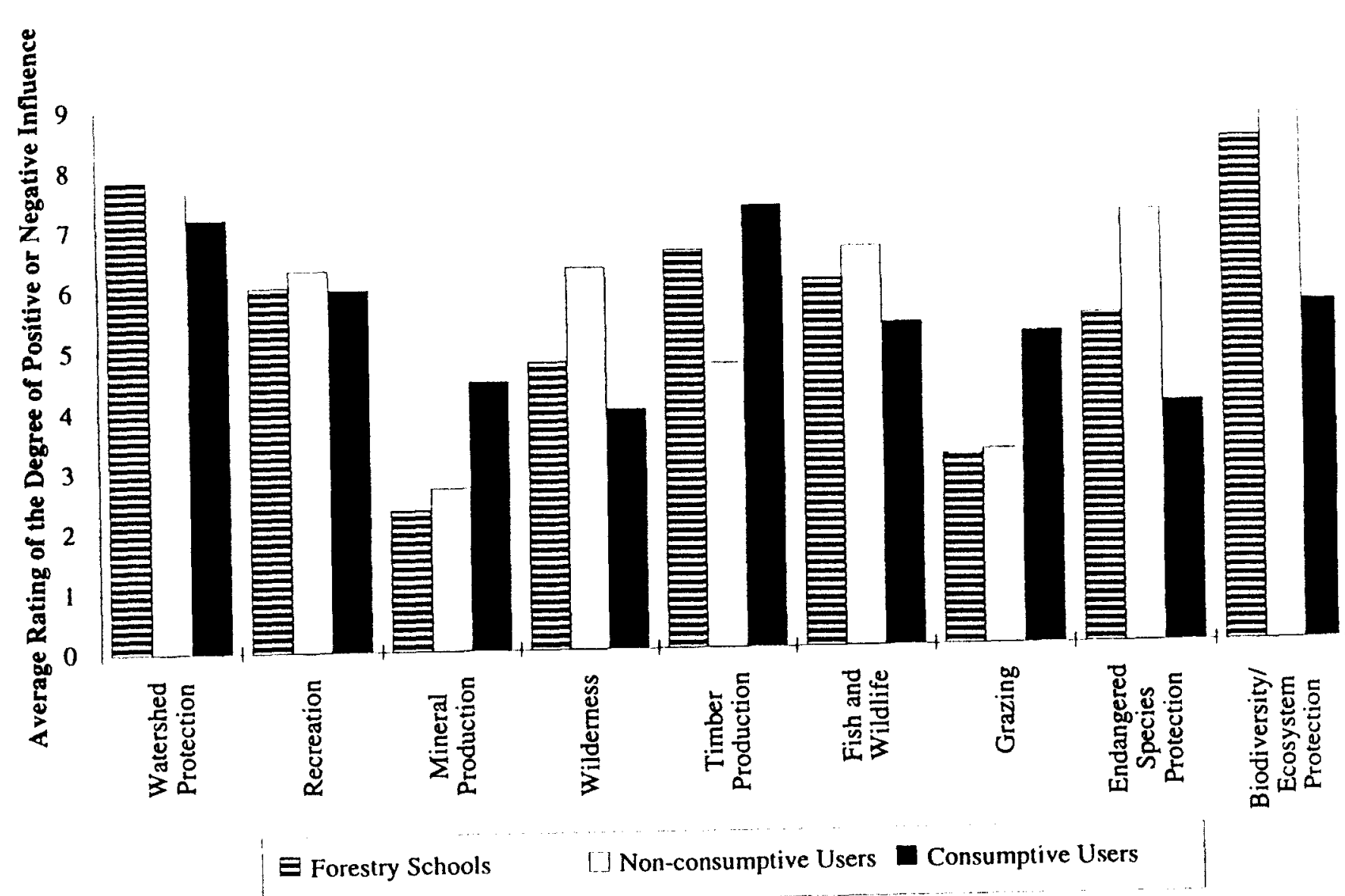

\section{External and Internal Forces for Desired Future Change}

Respondents next were asked to indicate the amount of influence they felt various external and internal forces would have during the next five years in promoting change from the Forest Service's current priorities to the group's desired priorities for the agency (which they had indicated in response to the previous question). Although figures are not provided for the results to this question, in most cases the factors perceived to have influenced past change (either positively or negatively) were believed by each of the respective groups to be likely to continue to influence future change. There were a couple of notable exceptions, however. Although non-consumptive users and forestry school heads viewed the White House and Congress as negative influences on past change, both groups anticipated the White House to be a positive influence for change in the next five years. This result may reflect optimism about the then-new Democratic president, Bill Clinton, who emphasized the environment as a priority in his presidential campaign. (The survey was undertaken at the very beginning of the Clinton presidency, and therefore does not reflect these groups' views on whether or 
not he lived up to their expectations.) In addition, non-consumptive users anticipated Congress to be a positive future influence, while forestry school heads expected Congress to continue to be a somewhat negative influence. Although consumptive users believed that both the White House and Congress would continue to be negative influences, they anticipated the White House to be an even more negative influence in the next five years than it had been in the past. Again, this may reflect expectations based on the outcome of the 1992 presidential election.

Another notable contrast is that, although non-consumptive users and forestry school heads viewed the Washington Office leadership and staff of the agency as having been somewhat negative influences on past change, both groups anticipated these would be positive influences on change in the future. Consumptive users, on the other hand, anticipated the Washington Office leadership and staff would continue to be negative influences.

In most other respects, groups that tended to see various external and internal factors as positive or negative influences on the Forest Service in the past perceived that these factors would continue to be significant influences on the agency in the future. As with influences on past change, external forces were anticipated to have a more significant impact on future change than were internal factors within the agency.

\section{Summary and Conclusions}

The objectives of this study were to assess the perceptions of National Forest user groups and of forestry school heads regarding the magnitude, nature, and source of past change in the Forest Service, and the need and likely source for future change. The survey concludes that the three surveyed groups clearly perceive the Forest Service to be changing. On average, non-consumptive users and forestry school heads saw the agency as heading in a positive direction, while consumptive users felt the opposite. It seems logical empirically to conclude that net change must be occurring in the direction of the priorities of the user group that is most pleased with the Forest Service and away from those of the user group that is most unhappy with the agency, i.e., towards nonconsumptive forest uses and away from the agency's historical commodity focus. This conclusion is bolstered by the fact that, while non-consumptive users felt that almost every employee category within the Forest Service was likely to have a positive influence, consumptive users just as consistently held to the contrary. A net movement toward non-commodity forest uses also was illustrated by the result that all three groups felt that the agency had increased its emphasis on all non-consumptive activities listed on the questionnaire-watershed protection, recreation, wilderness, fish and wildlife, endangered species, and biodiversity/ecosystem protection-while the commodity uses-grazing, mining, and timber-received ratings of either relatively small increases in emphasis, or decreases.

These results corroborate recent surveys of USFS employees that have observed a similar trend in changes in the attitudes and values of agency personnel (Kennedy, Krannich, Quigley, \& Cramer, 1993; Brown \& Harris, 1992a, 1992b; McCarthy, Sabatier, \& Loomis, 1991). In addition, the only employee survey to ask agency staff directly about their perceptions of change within the agency also found that increased responsiveness to the public and increased emphasis on non-commodity uses were cited most frequently as the most important positive changes to occur in the agency in the past decade (Mohai, Stillman, Jakes, \& Liggett, 1994; Mohai \& Jakes, in press). Farnham's quantitative analyses of changes in Forest Service budget requests and appropriations, and changes in recreation, fish and wildlife; and timber 
management activities also found evidence of agency movement in this direction (Farnham, 1995; Farnham, Taylor, \& Callaway, 1995; Famham \& Mohai, 1995).

However, despite their opinion that the agency was heading in the right direction, non-consumptive users, and to a lesser degree forestry schools, still feel that the agency is dominated by a focus on commodity production and therefore has further to go before achieving the groups' desired forest use priorities. Recent surveys of USFS employees by Mohai, Stillman, Jakes, and Liggett (1994), Kennedy, Krannich, Quigley, and Cramer (1993), and Brown and Harris (1992a) all found that agency employees shared this same belief. This indicates that the personal views of USFS employees are aligned more closely with non-consumptive users and forestry schools than with consumptive users. Such a finding seemingly is counter to Twight and Lyden's (1988) early conclusion, based on their 1981 survey, that the views held by Forest Service district rangers had more in common with forest utilizers than with environmentalists. However, rather than a contradiction of this earlier survey, our results may be indicative of significant growth and influence of forces for change both outside and within the agency in the years since Twight and Lyden's study, and of the fact that change within the Forest Service is a relatively recent phenomenon. Indeed, the groups surveyed in this study perceived that most change within the Forest Service has occurred since the late 1980 s.

While perceptions of the sources of agency change varied widely among the surveyed user groups, external forces tended to outweigh internal forces, on average, in the magnitude of perceived influence on both past and future change. In particular, the courts, White House, Congress, and interest groups, as well as some of their manifestations (e.g., NEPA, NFMA, legal challenges, the forest planning process, and public involvement), were rated as having especially sizable influences on the Forest Service. Such a result corroborates several studies that have found certain external forces for change, such as Congress and the courts, to have had significant impacts on the agency and to be increasing their pressure on and involvement in its decisionmaking (Farnham, 1995; Jones \& Callaway, 1995; Jones \& Taylor, 1995; Tipple \& Wellmann, 1991; Kennedy, 1988).

As a result, it may be that both the Twight and Culhane schools of thought on change in the Forest Service are right. Twight's conclusions regarding the Forest Service's internal obstacles and resistance to change may have been an accurate description of the agency in the early 1980s; but, given the unprecedented growth in external demands and pressures on the agency, these forces now may be strong enough to overcome internal resistance, and hence slowly may be forcing the agency to be responsive to pressures for change, as Culhane observed.

Despite the emphasis on external forces as the dominant vehicles for agency change, the survey results also indicate that seeds of change exist within the agency itself. This is illustrated particularly well by the fact that the forestry schools and nonconsumptive users, the two groups that viewed the agency as moving in a positive direction, ranked all aspects of the agency as having a positive influence. Again, such a finding is consistent with the results of previously-mentioned surveys of USFS employees that observed changes in employee values and attitudes (Mohai, Stillman, Jakes, \& Liggett, 1994; Brown \& Harris, 1992a; Kennedy, Krannich, Quigley, \& Cramer, 1993).

Specifically, our survey indicates that the influx of historically underrepresented personnel is perceived to have a role in agency change (positive for non-consumptive users and forestry schools, negative for consumptive users), but is not necessarily the driving internal force for change (note also Thomas \& Mohai's [1995] findings); other employee categories, such as researchers and regional and district staff, 
drew higher influence ratings. Non-foresters generally were seen as having a more significant impact than women and minorities, and non-consumptive users overall felt that "workforce diversification" had a greater positive impact on past change than did forestry schools. In the eyes of both non-consumptive and consumptive users, however, AFSEEE had a greater influence on agency change than had historically underrepresented personnel and most other internal forces for change, although the two user groups disagreed on the nature of that influence. Such a finding seems to give credence to the significance that Brown and Harris (1992b) have attributed to this employee organization.

Another significant survey result was that forestry schools tended to agree most often with non-consumptive, rather than consumptive, user groups. Such a finding seems to indicate that traditional forestry programs may be beginning to undergo a process of change themselves away from their traditional focus on timber production (Twight, 1983) and towards a more holistic, ecosystem focus. The implications are significant; $60 \%$ of Forest Service line officers, the agency personnel who have policy decisionmaking authority, have received their highest degree in forestry (Mohai, Stillman, Jakes, \& Liggett, 1994). As a result, the focuses and biases of the forestry school programs that agency personnel attended have the potential to impact greatly the management of the National Forests, although admittedly there will be a lag time between changes in forestry school curriculums and the subsequent movement of forestry school graduates into leadership positions with the agency.

In addition to providing valuable insights on the subject of change in the Forest Service, these survey results provide valuable feedback to the agency regarding its constituent groups' views on its performance in managing the National Forests. They also are useful in highlighting common views on National Forest uses and management, as well as the areas of greatest disagreement. Our study showed, not surprisingly, that there are huge differences among user groups' expectations about the desired level of commodity output from America's National Forests. However, despite the differences, it is interesting to note that both groups, as well as the forestry school heads, included watershed management and recreation in their top-five priority uses and objectives for the National Forests, with watershed management being rated as second in importance by all three surveyed groups. Such a result should be both useful and heartening to the agency and to policymakers as they seek areas of common ground and consensus in the management of our National Forests.

Elise S. Jones is the natural resources legislative assistant for United States Representative Elizabeth Furse, who represents the First District of Oregon. Ms. Jones has a B.S. in natural resources from Cornell University and has worked on federal environmental policy issues in Washington, DC since 1989. At the time of this research, she was a graduate student at the School of Natural Resources and Environment of the University of Michigan, Ann Arbor, where she went on to receive an M.S. in natural resources policy.

Paul Mohai is an associate professor in the School of Natural Resources and Environment at the University of Michigan, Ann Arbor. He is principal investigator of the University of Michigan Forest Service Survey, which examined Forest Service employees' views about change and the need for change in the agency. He also is a past principal investigator of the University of Michigan's Detroit Area Study, which in 1990 examined black and white differences in concerns about environment quality issues. He teaches courses in environmental sociology and natural resources policy at 
the University of Michigan, and has published widely on the topics of environmental attitudes and activism, natural resource agency decisionmaking, and environmental justice.

\section{References}

Ackerman, S. (1990). Observations on the transformation of the Forest Service: The effects of the National Environmental Policy Act on U. S. Forest Service decision making. Environmental Law, 20 (2), 703-734.

Association of Forest Service Employees for Environmental Ethics (AFSEEE). (1992). AFSEEE vision. Organizational fact sheet. Eugene, Oregon: Author.

Brown, G. (1993). AFSEEE and bottom-up change in the Forest Service. Inner Voice, 4 (1), 7-8.

Brown, G., \& Harris, C. C. (1992a). The U. S. Forest Service: Changing of the guard. Natural Resources Journal, 32, 449-466.

Brown, G., \& Harris, C. C. (1992b). The U. S. Forest Service: Toward the new resource management paradigm? Society \& Natural Resources, 5, 231-245.

Brown, G., \& Harris, C. C. (1993). The implications of workforce diversification in the U. S. Forest Service. Administration and Society, 25 (1), 85-113.

Burkholder, S. (1992). Elections '92. E Magazine, 3 (2), 38-47.

Clarke, J. N., \& McCool, D. (1985). Staking out the terrain: Power differentials among natural resource management agencies. Albany: State University of New York Press.

Culhane, P. J. (1977). Politics and public lands: Local policy processes of the U. S. Forest Service and the Bureau of Land Management. Unpublished doctoral dissertation. Evanston, IL: Northwestern University.

Culhane, P. J. (1981). Public lands politics: Interest group influence on the Forest Service and the Bureau of Land Management. Baltimore, MD: Johns Hopkins University Press.

Dana, S. T., \& Fairfax, S. K. (1980). Forest and range policy. New York, NY: McGraw-Hill Book Company.

Dillman, D. A. (1978). Mail and telephone surveys: The total design method. New York, NY: Wiley Publishing Co.

Durbin, K. (1990, October 15). Politics helped delay NW timber management plan. The Oregonian, pp. 711.

Encyclopedia of associations. (1992). Detroit, MI: Gale Research Company.

Farnham, T. (1995). Forest Service budget requests and appropriations: What do analyses of trends reveal? Policy Studies Journal, 23 (2), 253-267.

Farnham, T., \& Mohai, P. (1995). National forest timber management over the past decade: A change in emphasis for the Forest Service? Policy Studies Journal, 23 (2), 268-280.

Farnham, T., Taylor, C. P., \& Callaway, W. (1995). A shift in values: Non-commodity resource management and the Forest Service. Policy Studies Journal, 23 (2), 281-295.

Jones, E. S., \& Callaway, W. (1995). Neutral bystander, intrusive micromanager, or useful catalyst? The role of Congress in effecting change within the Forest Service. Policy Studies Journal, 23 (2), $337-350$.

Jones, E. S., \& Taylor, C. P. (1995). Litigating agency change: The impact of the courts and administrative appeals process on the Forest Service. Policy Studies Journal, 23 (2), 310-336.

Kaufman, H. (1960). The forest ranger: A study in administrative behavior. Baltimore, MD: Johns Hopkins University Press.

Kennedy, J. J. (1988). Legislative confrontation of groupthink in U. S. natural resource agencies. Environmental Conservation, 15 (2), 123-128.

Kennedy, J. J. (1991). Integrating gender diverse and interdisciplinary professionals into traditional United States Department of Agriculture-Forest Service culture. Society and Natural Resources 4, 165.

Kennedy, J. J., Krannich, R. S., Quigley, T. M., \& Cramer, L. A. (1993). Employee perceptions of USDAForest Service values and the agency reward system. Paper presented at the 1993 Society of American Foresters' Annual Convention. Indianapolis, $\mathbb{I N}$.

McCarthy, C., Sabatier, P., \& Loomis, J. (1991). Attitudinal change in the Forest Service: 1960-1990. Paper presented at the 1991 Annual Meeting of the Western Political Science Association. Seattle, WA.

Mohai, P. (1987). Public participation and natural resource decision-making: The case of the RARE II decisions. Natural Resources Journal, 27 (1), 123-155.

Mohai, P., \& Jakes, P. (in press). The Forest Service in the 1990's: Is it heading in the right direction?-A view from agency employees. Journal of Forestry. 
Mohai, P., Stillman, P., Jakes, P., \& Liggett, C. (1994). Change in the USDA Forest Service: Are we heading in the right direction? General Technical Report NC-172. St. Paul, MN: United States Department of Agriculture, Forest Service, North Central Forest Experiment Station.

Parent, S. M. (1992). The National Forest Management Act: Out of the woods and back to the courts? Environmental Law, 22 (2), 699-702.

Thomas, J. C., \& Mohai, P. (1995). Racial, gender, and professional diversification in the Forest Service from 1983 to 1992. Policy Studies Journal, 23 (2), 296-309.

Tipple, T. J., \& Wellmann, J. D. (1991). Herbent Kaufman's forest ranger thinty years later: From simplicity and homogeneity to complexity and diversity. Public Administration Review, 51 (5), 421-428.

Twight, B. W. (1983). Organizational value and political power: The Forest Service versus the Olympic National Park. University Park: Pennsylvania State University Press.

Twight, B. W., \& Lyden, F. J. (1988). Multiple use vs. organizational commitment Forest Science, 34 (2), $474-486$.

Twight, B. W., \& Lyden, F. J. (1989). Measuring forest service bias. Journal of Forestry , 87 (5), 35-41.

United States General Accounting Office. (1991). Federal affirmative employment: Status of women and minority representation in the federal workforce. Washington, DC: Author. GAO/T-GGD-922. 
This document is a scanned copy of a printed document. No warranty is given about the accuracy of the copy. Users should refer to the original published version of the material. 